\title{
High-pressure small-angle X-ray scattering (SAXS) cell for biological solutions and soft materials
}

Durgesh K. Rai, Richard E. Gillilan, Qingqiu Huang, Robert Miller, Edmund Ting, Alexander Lazarev, Mark W. Tate and Sol M. Gruner

\section{Supplemental Information}

\section{Window Thickness, transmission, and sample volume}

BioSAXS samples are generally dilute solutions of weakly scattering molecules requiring careful, consistent background subtraction. X-ray transparent window material is necessary to hold liquid samples, but unavoidably competes with the inherently weak sample signal. At the most basic level, window material absorbs $\mathrm{X}$-rays, reducing the transmitted intensity. But the problem with X-ray windows is more complex: surface roughness of the material creates high background levels of scattering at the smallest angles. X-ray windows can also have defects such as scratches, inclusions, and inhomogeneities at the microscopic level. All of these effects can vary across the window surface, so any displacement of the sample cell relative to the X-ray beam can result in irreproducible background scatter. X-ray window material can also exhibit ordering on the molecular scale that results in scattering rings, bands, or diffraction spots. Ordered scattering reduces signal-to-noise levels but subtracts out of scattering profiles. For BioSAXS conducted at ambient pressure, choosing window material as thin as possible minimizes all these effects. Unfortunately, thin windows are not compatible with high pressure.

High-pressure BioSAXS requires X-ray transparent windows that can resist enormous forces without failure. The elastic limit of a window can be estimated for an unclamped circular plate against a circular aperture (Ando et al., 2008, Holzapfel \& Isaacs, 1997) as

$$
P_{\max }=\frac{8}{3}\left(\frac{T}{R}\right)^{2} \frac{Y}{3+\sigma}
$$


The maximum sustainable pressure $P \max$ for a window, is a function of window thickness, $T$, hole radius, $R$, yield strength of the window material, $Y$, and the Poisson ratio of the window material, $\sigma$. The yield strength, the point at which the deformation of diamond becomes nonlinear under stress, is not a well-controlled quantity, nor is tensile strength, the point at which diamond actually breaks; the values are heavily dependent upon the quality of the diamond. Generally, single-crystal natural diamond is considered highest in strength, followed closely by HPHT (high pressure high temperature) diamond, the type used here, then CVD (chemical vapor deposition) as the weakest (Field, 2012). Values of Y reported in the literature vary widely, arguing for use of a conservative approach. Ando originally used a conservative value of $\mathrm{Y}=750 \mathrm{MPa}$ (Ando et al., 2008). The low value was probably sensible at the time, given that diamond windows were being re-purposed from broken diamond anvil cells. Brooks et al., have used $\mathrm{Y}=1.4 \mathrm{GPa}$ for the CVD diamond used in their HP-SAXS design (Brooks et al., 2010). Field (Field, 2012) suggests 3.75 GPa for a tensile strength based on indentation experiments corresponding to "good quality diamonds having sharp-ended defects of length about $0.5 \mu \mathrm{m}$ " (Field, 2012). Using this number and a Poisson ratio of $\sigma=0.1$ (Field, 2012), a diamond window of thickness $T=0.5 \mathrm{~mm}$ with radius $R=0.75 \mathrm{~mm}$ will survive $\mathrm{P}_{\max }=1.4 \mathrm{GPa}$, safely in excess of any pressures we can currently generate with this setup. A plot of $\mathrm{P}_{\max }$ as a function of window thickness is given in Figure $\mathrm{S} 1$. The cell design, as implemented here, encloses the windows inside a metal vacuum chamber, consequently, the main risk for rupture is damage to the downstream X-ray detector hardware.

While the X-ray absorption introduced by thick windows can be compensated by increased exposure times and bright sources, the intrinsic scattering background produced by the window material competes with the sample signal and the only option to maintain sensitivity is to use a thicker volume of sample. For this analysis, we ignore the thin $7.5 \mu \mathrm{m}$ polyimide sample cell windows. The classic expression for scattering intensity, $I$, as a function of sample path length, $d$, is $I \propto d \exp \left(-\mu_{\mathrm{water}} d\right)$. The maximum intensity is found at $d=1 / \mu_{\text {water, }}$ which is the optimum thickness for a sample. The X-ray 
mass attenuation of water is strongly dependent on wavelength: $\mu_{\mathrm{water}} \approx 3 \lambda^{3} \mathrm{~cm}^{-1}$. So, for the commonly used BioSAXS wavelength of $1.24 \AA$ (10 keV), optimum sample thickness would be $\mathrm{d} \approx 1.8 \mathrm{~mm}$. At $14 \mathrm{keV}$ (this study), $\mathrm{d} \approx 4.9 \mathrm{~mm}$. Looking back at the intensity formula, the improvement in sample scattering from working at higher energy would be a factor of $4.9 / 1.8=2.7$. At the same time, the thickness of the $2 \times 0.5 \mathrm{~mm}$ diamond windows (and corresponding background scattering) is fixed, so the transmission has improved: from $46 \%$ at $10 \mathrm{keV}$ to $75 \%$ at $14 \mathrm{keV}$ (Henke et al., 1993).

Two different configurations of the HP-SAXS cell have been considered: one for routine work (a maximum pressure of $400 \mathrm{MPa}$ using $0.5 \mathrm{~mm}$ thick windows), and one for higher pressure work (a maximum of $700 \mathrm{MPa}$ using $1.0 \mathrm{~mm}$ thick windows). Figure S2 gives a comparison of the transmissions of the two cells and their components. At $14 \mathrm{keV}$ (this study), the transmissions are relatively similar. The main practical difference is therefore not so much transmission, but lower background scattering inherent with thinner windows.

The use of high X-ray energy in combination with sample thickness allows us to maximize the sensitivity of the instrument by minimizing the scattering contribution of the window materials. In contrast, biological samples are often precious and difficult to prepare, so there are practical limits to how thick a sample can be. Nielsen has already noted that a sample cell aperture must be big enough to avoid parasitic scattering from the tail of the X-ray beam (Nielsen et al., 2012). In practice, a sample cell aperture must be at least as wide as the final beamline optics guard slits, typically $0.7 \mathrm{~mm}$ for CHESS ID7A. Thus, for a $3.5 \mathrm{~mm}$ sample path, with $0.7 \mathrm{~mm}$ diameter X-ray aperture, the illuminated volume is a modest $5.4 \mu \mathrm{l}$. In practice, additional sample dead volume is also necessary to accommodate the seal between the sample and pressure medium (water), to ensure that no beam impinges on the plastic, and to allow for practical sample loading. Our current $3.5 \mathrm{~mm}$ design requires approximately $30-40 \mu \mathrm{l}$, a reasonable amount by traditional BioSAXS standards. 
Beyond sample consumption, there are two other considerations that limit the value of high-energy measurements: uncertainty in sample-to-detector distance and achievable small angle. This first of these is a small effect: a sample-to-detector distance of $1700 \mathrm{~mm}$ and a sample thickness of $5 \mathrm{~mm}$, for example, would lead to an insignificantly small error of only $\sim 0.3 \%$ in $q$-space. The more serious consideration is minimum achievable $q$. Measurements of scattering at smallest angles are limited by the diameter of the beamstop, a value that is determined by the maximum allowable background scattering level near the direct beam. Recalling that $q=4 \pi \sin \theta / \lambda$ and fixing sample-to-detector

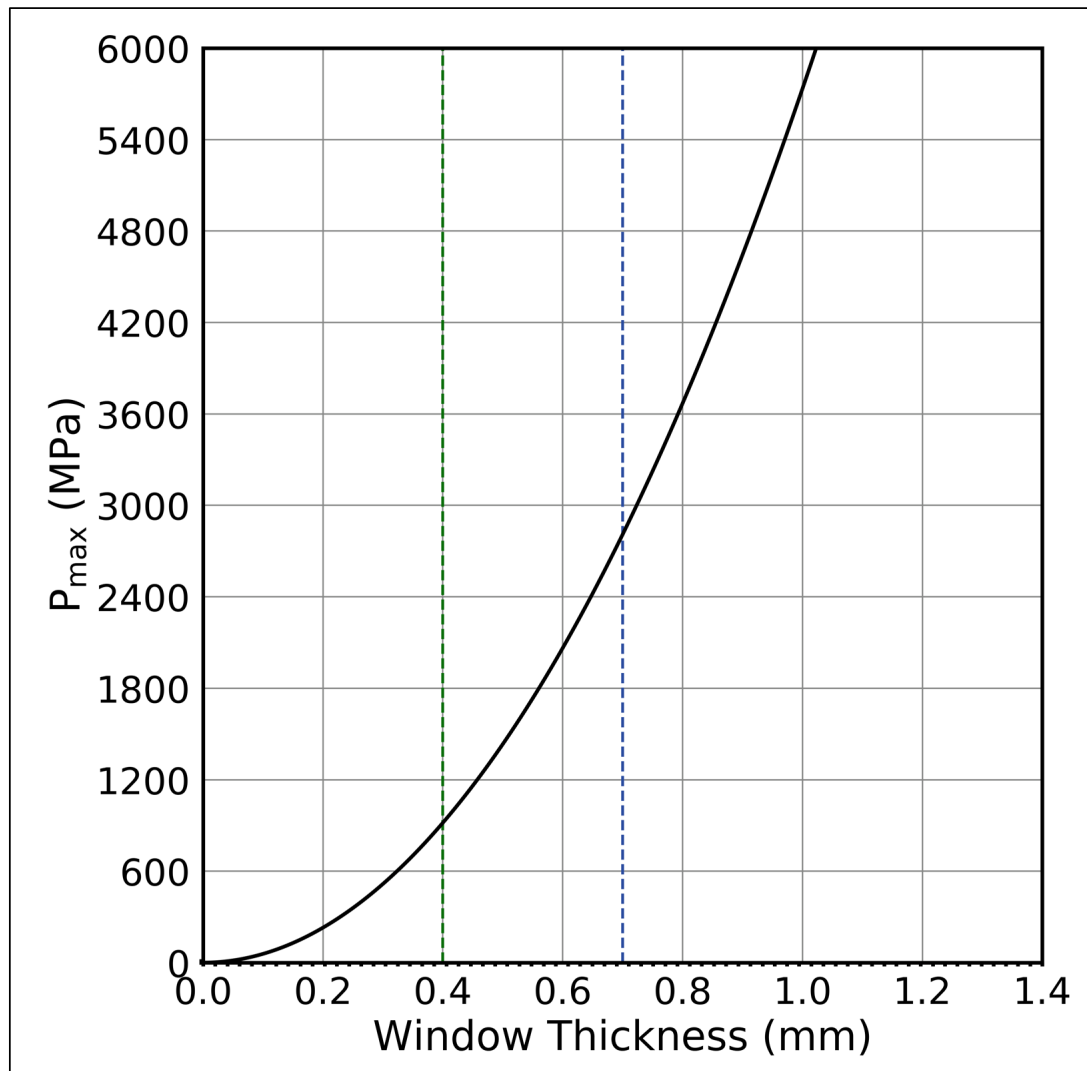

Figure S1: Maximum pressure for a diamond window as a function of thickness

distance and beamstop (holding $\theta$ constant), $q_{\min }=0.008 \AA^{-1}$ at $10 \mathrm{keV}(1.24 \AA$ ) becomes $q_{\text {min }}=(1.24 / 0.89)^{*} 0.008 \AA^{-1}=0.011 \AA^{-1}$ at $14 \mathrm{keV}(0.89 \AA)$. Energy thus limits the maximum size of objects that can be measured. While BioSAXS measurements at CHESS have been performed with X-rays as high as $32 \mathrm{keV}$, we have found in practice that 
energies much above $20 \mathrm{keV}$ start to seriously restrict the sizes of biomolecules that can be studied. Further, higher energies begin to require specialized detector and beamline design.

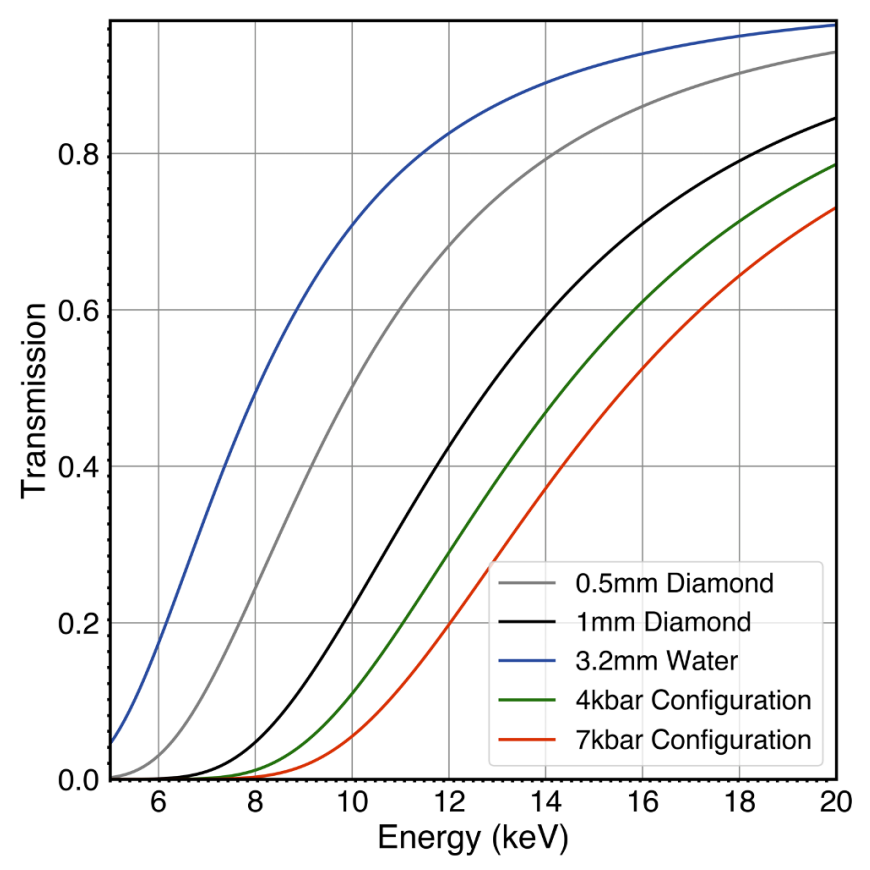

Figure S2: X-ray transmission factors of diamond windows and water in the high pressure cell. 


\section{Temperature Equilibration}

A Thermotek T255p chiller (ThermoTek Inc. Flower Mound, TX) was used to measure the thermal response of the high pressure cell. The three temperatures: coolant, RTD mounted under the pressure water inlet, and the thermocouple at sample position were monitored and the results shown in Figures S3.
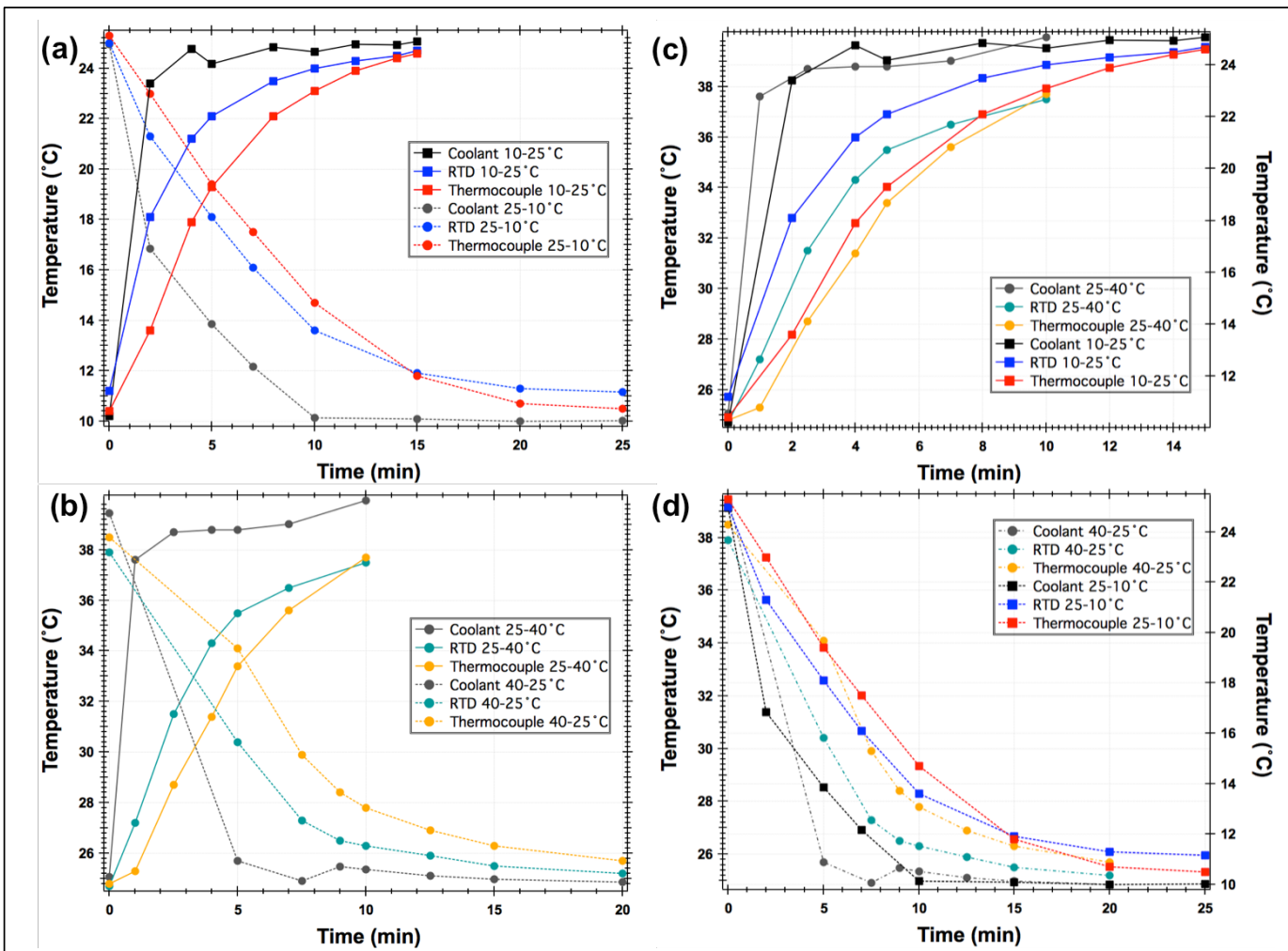

Figure S3: Coolant readout, SAXS cell mounted RTD and thermocouple at sample position temperatures while scanning (a) $10^{\circ} \mathrm{C}-25^{\circ} \mathrm{C}$ and $25^{\circ} \mathrm{C}-10^{\circ} \mathrm{C}$, (b) $25^{\circ} \mathrm{C}-40^{\circ} \mathrm{C}$ and $40^{\circ} \mathrm{C}-25^{\circ} \mathrm{C}$; and (c) Ramp Up $25^{\circ} \mathrm{C}-40^{\circ} \mathrm{C}$ and $10^{\circ} \mathrm{C}-25^{\circ} \mathrm{C}$ and (d) Ramp Down $40^{\circ} \mathrm{C}-25^{\circ} \mathrm{C}$ and $25^{\circ} \mathrm{C}-10^{\circ} \mathrm{C}$, with time. 


\section{Protein Standards}

The gene encoding the Streptomyces rubiginosus glucose isomerase (srGI) was optimized and synthesized by Bio Basic Inc with a BamHI site at the $5^{\prime}$ end and a XhoI site at the 3' end. The DNA was amplified by PCR. After being cut by BamHI and XhoI, the DNA was inserted into the expression vector pSUMO and pQE80 respectively using the corresponding sites. The recombinant plasmid pSUMO-srGI was transferred into E. coli BL21(DE3) for protein expression, which was induced at $18^{\circ} \mathrm{C}$ for 20 hours with $0.3 \mathrm{mM}$ IPTG. The cells were harvested by centrifugation and then suspended in binding buffer ( $500 \mathrm{mM} \mathrm{NaCl}, 50 \mathrm{mM}$ Tris- $\mathrm{HCl}, \mathrm{pH} 8.5,2 \mathrm{mM} \mathrm{MgCl}_{2}, 10 \mathrm{mM}$ imidazole). Cell lysis was carried out by sonication. After centrifugation, the supernatant was applied to a nickel affinity column. After protein binding, the column was washed thoroughly with 100 volumes of binding buffer followed by 10 volumes of washing buffer ( $500 \mathrm{mM} \mathrm{NaCl}, 50 \mathrm{mM}$ Tris- $\mathrm{HCl}$, pH8.5, 40mM imidazole). The protein was then eluted from the column with 5 volumes of elution buffer $(200 \mathrm{mM} \mathrm{NaCl}, 300 \mathrm{mM}$ imidazole- $\mathrm{HCl}, \mathrm{pH} 7.5)$. ULP1ase was added to the elute and incubated at $4^{\circ} \mathrm{C}$ overnight to cleave off the SUMO tag. After being concentrated, the protein was purified using a Superdex 200 column (GE) mounted on FPLC with an elution buffer containing $0.15 \mathrm{M} \mathrm{NaCl}, 0.5 \mathrm{mM}$ TCEP and $25 \mathrm{mM}$ Hepes- $\mathrm{NaOH}$ (pH7.4). The peak containing srGI was pooled and concentrated to around $20 \mathrm{mg} / \mathrm{ml}$, and stored at $80^{\circ} \mathrm{C}$. This protein does not contain any additional residues from the vector.

The recombinant plasmid pQE80-srGI was transferred into E. coli BL21(DE3) for protein expression, which was induced at $18^{\circ} \mathrm{C}$ for 20 hours with $0.3 \mathrm{mM} \mathrm{IPTG}$. The cells were harvested by centrifugation and then suspended in binding buffer $(500 \mathrm{mM}$ $\mathrm{NaCl}, 50 \mathrm{mM}$ Tris- $\mathrm{HCl}, \mathrm{pH} 8.5,2 \mathrm{mM} \mathrm{MgCl} 2,10 \mathrm{mM}$ imidazole). Cell lysis was carried out by sonication. After centrifugation, the supernatant was applied to a nickel affinity column. After protein binding, the column was washed thoroughly with 100 volumes of binding buffer followed by 10 volumes of washing buffer $(500 \mathrm{mM} \mathrm{NaCl}, 50 \mathrm{mM}$ Tris- $\mathrm{HCl}$, pH8.5, 40mM imidazole). The protein was then eluted from the column wit 
h 5 volumes of elution buffer $(200 \mathrm{mM} \mathrm{NaCl}, 300 \mathrm{mM}$ imidazole- $\mathrm{HCl}, \mathrm{pH} 7.5)$. After being concentrated, the protein was purified using a Superdex 200 column (GE) mounted on FPLC with an elution buffer containing $0.15 \mathrm{M} \mathrm{NaCl}, 0.5 \mathrm{mM}$ TCEP and $25 \mathrm{mM}$ Hepes- $\mathrm{NaOH}$ (pH7.4). The peak containing srGI was pooled and concentrated to around $20 \mathrm{mg} / \mathrm{ml}$, and stored at $-80^{\circ} \mathrm{C}$. The His-Tag version of this protein contains additional residues MRGSHHHHHHGS from the vector at its N-terminus.

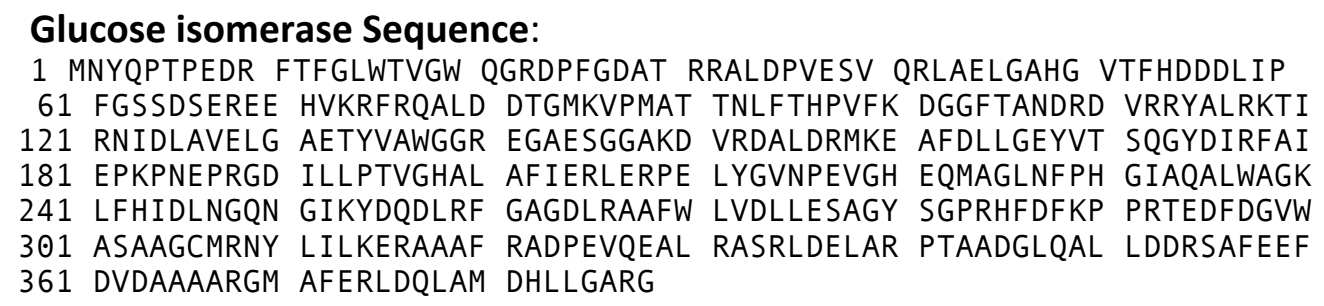

Dilute SAXS measurements ( 4.5 and $0.9 \mathrm{mg} / \mathrm{ml}$ ) were collected using glucose isomerase in $25 \mathrm{mM}$ HEPES buffer at pH 7.0 containing $150 \mathrm{mM} \mathrm{NaCl}$ and $3 \%$ glycerol. Concentrated SAXS measurements $(22 \mathrm{mg} / \mathrm{ml}, 17.9 \mathrm{mg} / \mathrm{ml})$ were measured in 150 $\mathrm{mM} \mathrm{NaCl}, 0.5 \mathrm{mM}$ TCEP and 25mM Hepes- $\mathrm{NaOH}$ (pH7.4). 


\section{Scattering data}

The supplementary data files for this paper are buffer-subtracted scattering files of glucose isomerase at specified concentrations and pressures. The 3-column text format with comment lines is readable by common SAXS data processing programs.
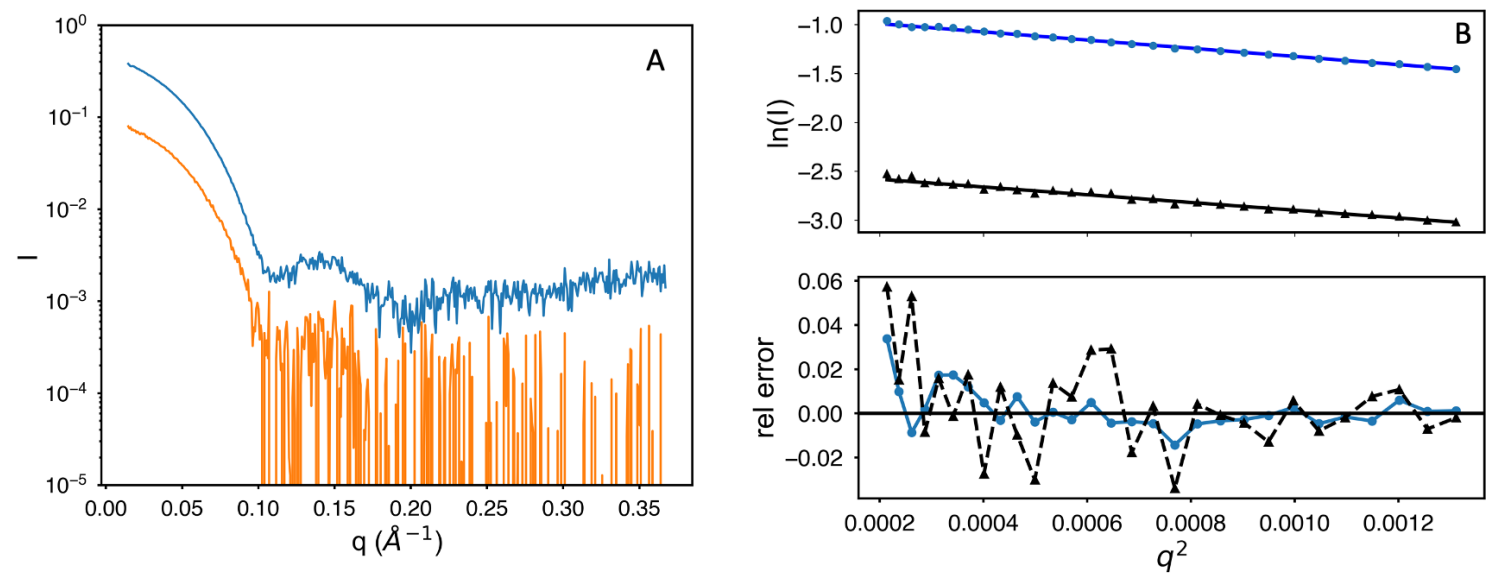

Figure S4: Profiles and Guinier plots of dilute glucose isomerase samples at ambient pressure. The upper profile in (A) is $4.5 \mathrm{mg} / \mathrm{ml}$, while the lower one in (A) is $0.9 \mathrm{mg} / \mathrm{ml}$. Guinier plots (B) are linear all the way to the minimum q value $\left(q_{\min }=0.0146 \AA^{-1}\right)$. Relative error between the data and the linear fits in $(\mathrm{B}$, lower $)$ is the ratio $\left(\mathrm{I}_{\text {data }}-\mathrm{I}_{\text {line }}\right) / \mathrm{I}_{\text {line }}$. 


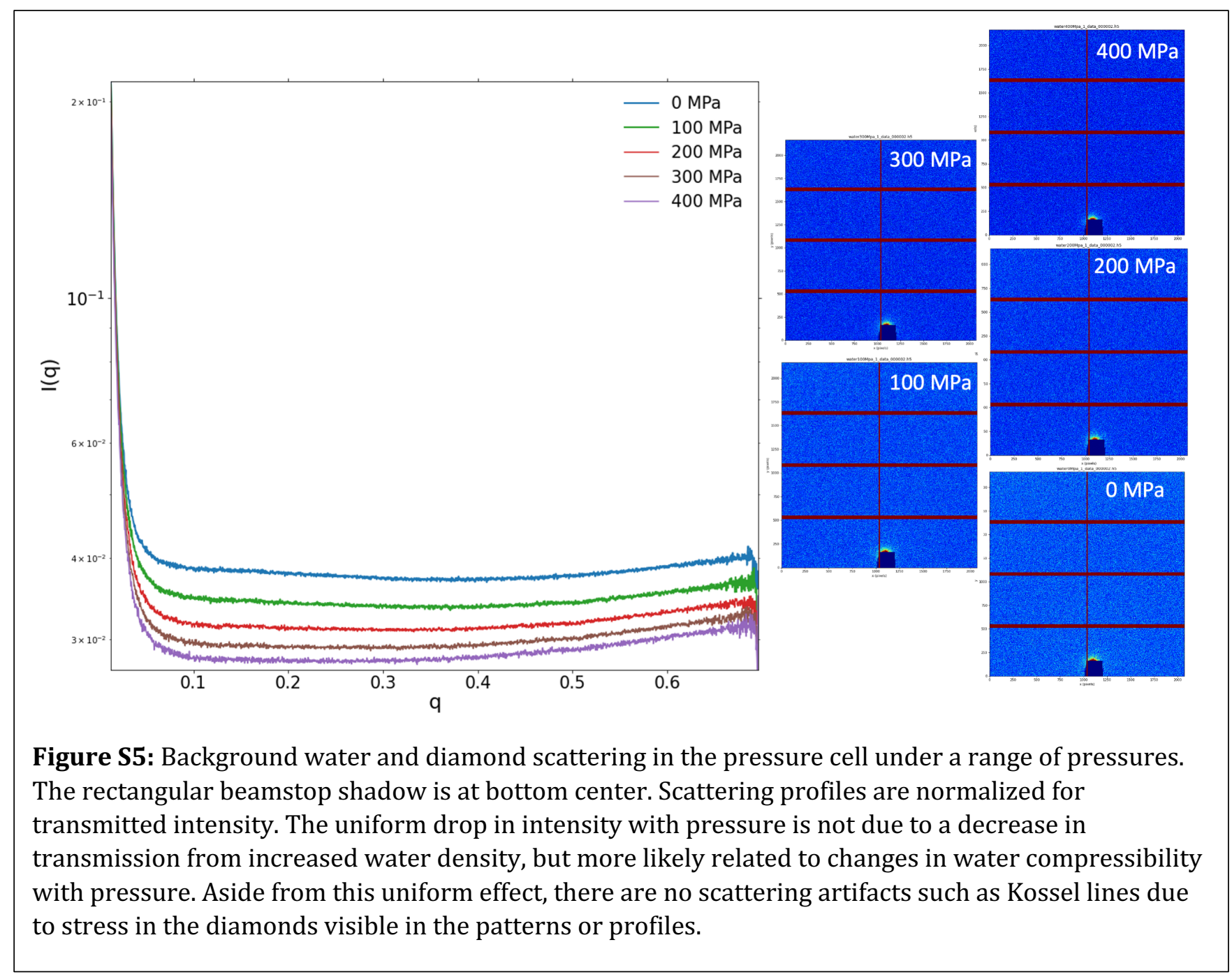



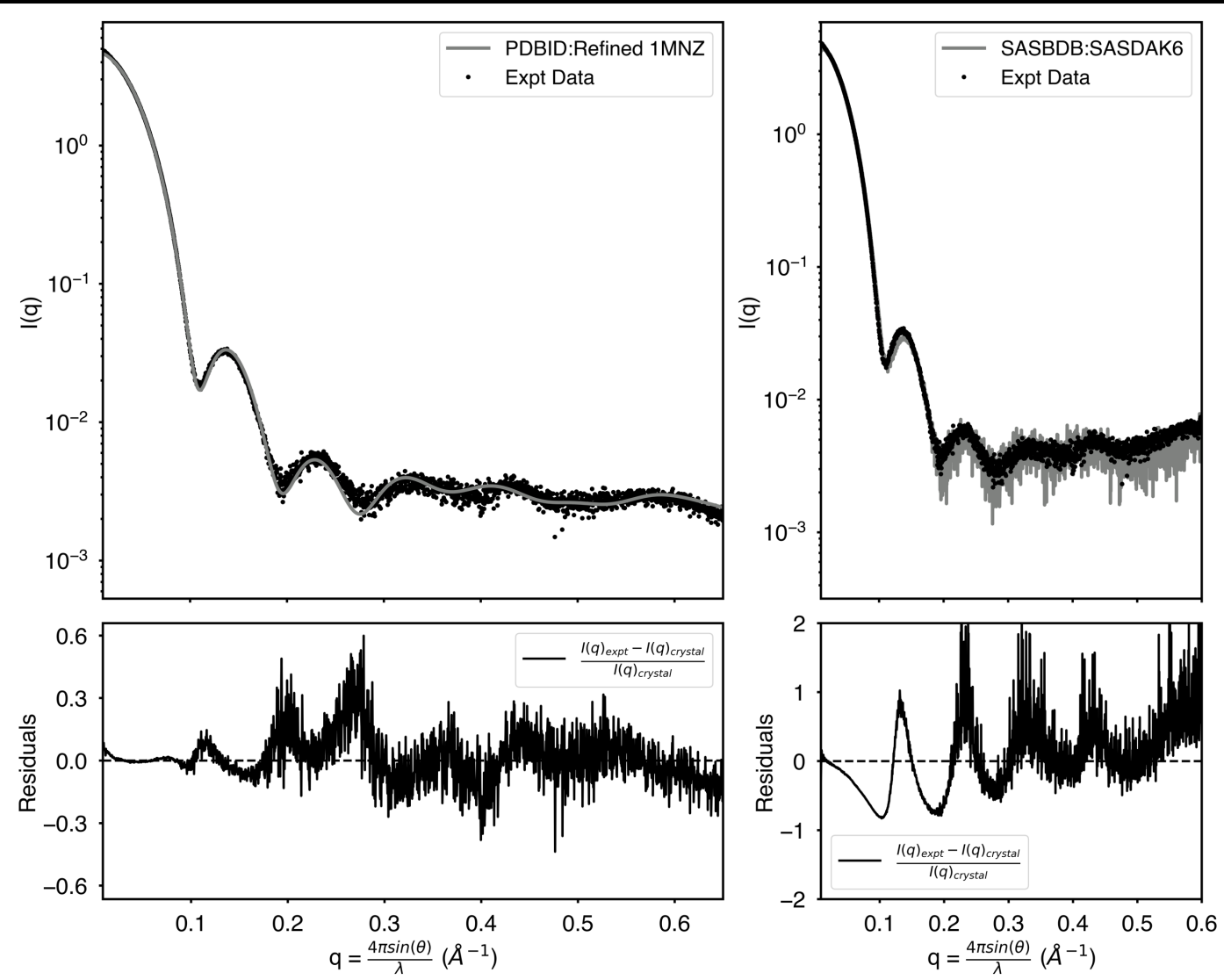

Figure S6: SAXS profile of glucose isomerase (GI) collected on the ID7A beamline at CHESS in the diamond cell at ambient pressure compared to profiles generated from the crystal structure (PDBID: $1 \mathrm{MNZ}$ ) by molecular dynamics $(\mathrm{A}, \mathrm{B})$ and a previously published dataset (SASBDB:SASDCK2; $\mathrm{C}, \mathrm{D})$. The GI construct measured at ID7A contained an additional N-terminal His-Tag. 


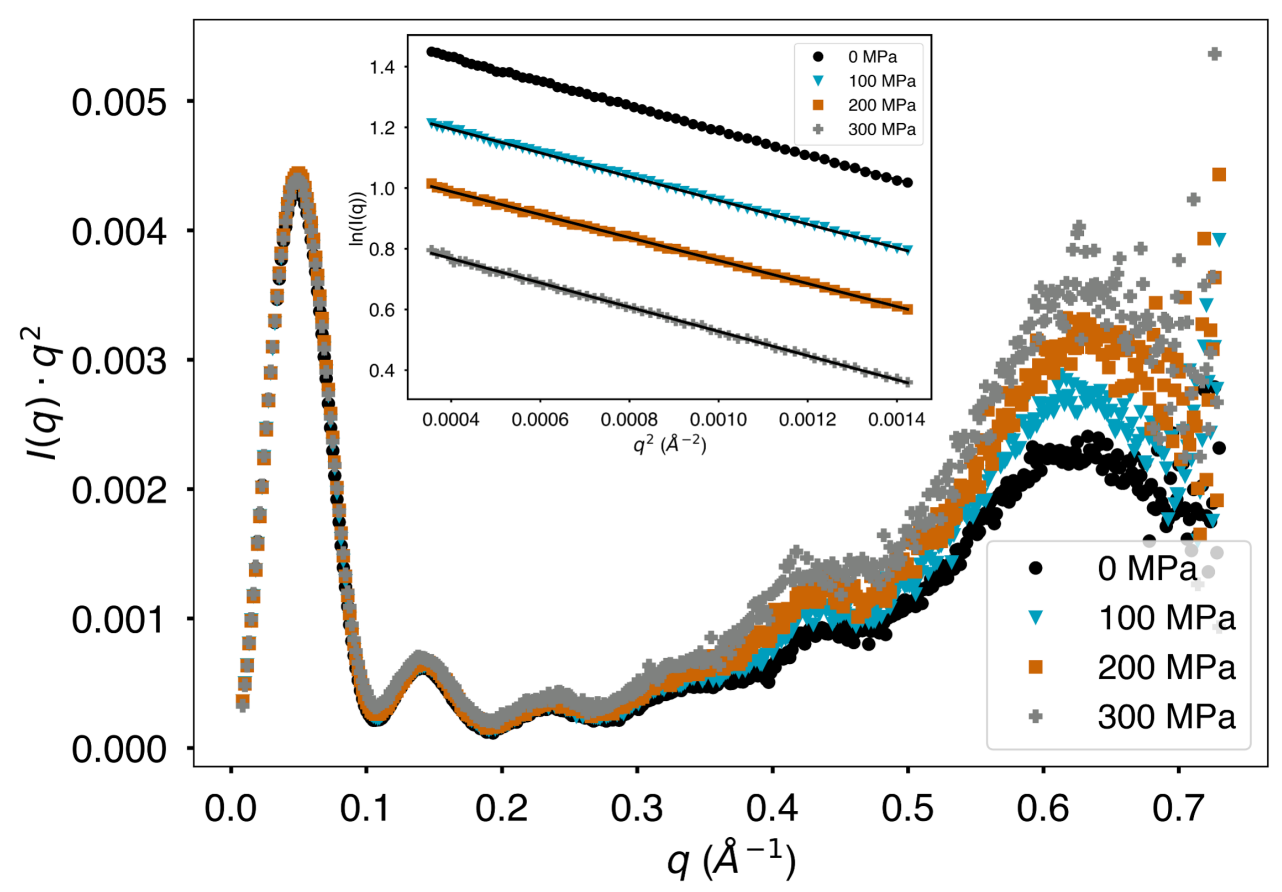

Figure S7: Guinier and Kratky plots of glucose isomerase under pressure. Inset Guinier plots show pressure-induced contrast changes. Kratky plots, superimposed for comparison, show minor structural change below $q=0.3 \AA^{-1}$ but diverge at wide angle.

\section{References}

Ando, N., Chenevier, P., Novak, M., Tate, M. W. \& Gruner, S. M. (2008). Journal of Applied Crystallography 41, 167-175.

Brooks, N. J., Gauthe, B. L., Terrill, N. J., Rogers, S. E., Templer, R. H., Ces, O. \& Seddon, J. M. (2010). Review of Scientific Instruments 81, 064103.

Field, J. (2012). Reports on Progress in Physics 75, 126505.

Henke, B. L., Gullikson, E. M., Davis, J.C. Atomic Data \& Nuclear Data Tables, (1993). 54 181342.

Holzapfel, W. B. \& Isaacs, N. S. (1997). High pressure techniques in chemistry and physics-a practical approach.

Nielsen, S. S., Møller, M. \& Gillilan, R. E. (2012). Journal of Applied Crystallography 45, 213223. 